\title{
Postpubertal Emergence of Hyperresponsiveness to Stress and to Amphetamine after Neonatal Excitotoxic Hippocampal Damage: A Potential Animal Model of Schizophrenia
}

Barbara K. Lipska, Ph.D., George E. Jaskiw, M.D., and Daniel R. Weinberger, M.D.

The constellation of major phenomena associated with schizophrenia (e.g., postpubertal onset, congenital hippocampal area damage, cortical functional deficits, limbic dopamine (DA) dysregulation, and vulnerability to stress) have been difficult to explain with a unitary animal model. Although it has been shown that rats develop increased mesolimbic DA transmission and reduced cortical $D A$ turnover following adult excitotoxic lesions of the ventral hippocampus (VH), the implications of early developmental VH lesions are not known. To determine the developmental sequelae of such changes, we produced ibotenic acid lesions of the ventral hippocampal formation in rats on the 7th day after birth (PD7). Motor activity in a novel environment, after saline injection and after $\mathrm{d}$-amphetamine administration were similar in control and lesioned rats at PD35. However, in early adulthood, at PD56, animals with the hippocampal lesion were hyperactive in each of these conditions. The emergence of the hyperactivity at PD56 could be prevented by pretreatment with haloperidol. Moreover, rats lesioned as neon.tes, in contrast to a similar lesion induced in adult animals, were also hyperresponsive to stress evaluated with a swim test. This latter effect is analogous to that seen after adult lesions of the medial prefrontal cortex, rather than after adult lesions of $\mathrm{VH}$, suggesting that the neonatal $\mathrm{VH}$ lesion may affect functional development of the medial prefrontal cortex. These results demonstrate that in rats with neonatally induced excitotoxic VH lesions, behavioral indices consistent with increased mesolimbic $D A$ responsivity to stressful and to pharmacologic stimuli emerge only in early adulthood. Homologous mechanisms may underlie certain aspects of the pathophysiology of schizophrenia. [Neuropsychopharmacology 9:67-75, 1993]
KEY WORDS: Hippocampus; Schizophrenia; Animal model; Dopamine; Locomotor activity; Neonatal lesion; Ibotenic acid

From the Clinical Brain Disorders Branch, Intramural Research Program (BKL, DRW), National Institute of Mental Health, Washington DC, and the Department of Psychiatry (GEJ), University Hospital, Cleveland, Ohio.

Address correspondence to: Barbara K. Lipska, Clinical Brain Disorders Branch, Intramural Research Program, National Institute of Mental Health, Neuroscience Center at St. Elizabeths, 2700 Martin Luther King Ave. SE, Washington, DC 20032.

Received December 23, 1992; revised February 16, 1993; accepted February 19, 1993.
On the whole, efforts to model in animals diverse phenomenologic aspects of schizophrenia have met with very limited success. Although early neurobiologic models emphasized primary perturbations in striatolimbic dopamine (DA) activity to account for the therapeutic effects of antidopaminergic drugs (Borison et al. 1977; Kornetsky and Markowitz 1978; Kokkinidis and Anisman 1980; McKinney and Moran 1981), they did not represent potentially explanatory mechanisms for either the cortical deficits (Buchsbaum et al. 1982; Weinberger et al. 1986; Goldberg et al. 1991; Berman and 
Weinberger 1991) or the postpubertal onset that also characterize this illness. The subsequent discovery that the prefrontal cortex could regulate subcortical DA activity (Pycock et al. 1980; Deutch et al. 1990; LeMoal and Simon 1991) offered a link between posited striatolimbic DA dysregulation and data implicating the prefrontal cortex in schizophrenia. Models based on primary prefrontal lesions were at variance, however, with observations that structural pathology in schizophrenia is most reliably observed in the hippocampal region and not in the prefrontal cortex (Bogerts et al. 1985; Jakob and Beckmann 1986; for review, see Hyde et al. 1991). But the hippocampal formation also participates in the regulation of the mesolimbic DA system (Kelley and Domesick 1982; Yang and Mogenson 1985; Groenewegen et al. 1987; Csernansky et al. 1988; Sesack and Pickel 1990). Indeed, we recently reported (Lipska et al. 1992) that an excitotoxic lesion of ventral hippocampal $(\mathrm{VH})$ formation in the adult rat enhanced spontaneous exploration and amphetamine induced locomotion, while inducing opposite changes in putative DA release/transmission in cortical (medial prefrontal cortex $[\mathrm{MPFC}]$ ) and limbic (nucleus accumbens [NAC]) fields innervated by the hippocampal formation (Goldman-Rakic et al. 1984; Ferino et al. 1987; Jay and Witter 1991).

All these animal models have a common shortcoming in that they depend on perturbations of the adult brain. Most data suggest that the anatomic changes, and particularly the temporal limbic abnormalities evident in schizophrenia, represent early developmental injury that remains clinically quiescent until adulthood (Weinberger et al. 1986; Weinberger 1987; Crow 1990; Fish et al. 1992; Stevens 1992). Although effects of brain injury are known to depend both on the developmental stage at which the injury occurs and on the postinjury interval, there are few paradigms in which an early, nonepileptiform lesion remains relatively "silent" until a later stage of development. Indeed, the opposite is generally the case. The immature brain demonstrates a high degree of functional compensation or sparing of behavioral function after early injury (Erinoff and Snodgrass 1986; Kolb and Whishaw 1989; Kolb and Gibb 1991) and, the degree of functionalsparing generally increases with the postinjury interval (Kennard 1936). Such observations mitigate against the neurodevelopmental hypothesis of schizophrenia, where an opposite process has been adduced (i.e., early successful sparing paradoxically fails by adulthood).

Because the profile of changes following excitotoxic lesion of the adult rat $\mathrm{VH}$ appeared to provide the bestfit adult animal model available, reproducing hippocampal formation damage, changes consistent with increased mesolimbic DA activity, and reduced cortical DA activity (Weinberger et al. 1988; Pickar et al. 1990; Davis et al. 1991), we evaluated the developmental specificity of these lesion-induced changes. In particular, we posited that the effects of early hippocampal lesions on limbic DA systems would not be attenuated by maturation (i.e., the expected "Kennard principle" would fail [Kennard 1936]) but would instead emerge with maturation (the putative "schizophrenia principle").

\section{MATERIALS AND METHODS}

\section{Surgery}

Pregnant Sprague-Dawley rats obtained at 14 days gestation (Zivic Miller Labs) were housed individually in breeding cages with a 12-hour light/dark cycle and fed ad libitum. Litters of four to eight male pups were formed. On the 7th day of age (PD7) and at a weight of 15 to $18 \mathrm{~g}$, pups within each litter were randomized to Sham or Lesion status and anesthetized by hypothermia (placed on wet ice for 10 to 20 minutes). After immobilizing a rat by taping it to a platform fixed to a stereotaxic Kopf instrument, an incision was made in the skin overlying the skull and $0.3 \mu$ of ibotenic acid (Sigma, $10 \mu \mathrm{g} / \mu \mathrm{l}$ ) or artifıcial cerebrospinal fluid was infused bilaterally using an infusion pump through a Hamilton needle into the ventral hippocampal formation at a rate of $0.15 \mu \mathrm{l} / \mathrm{min}(\mathrm{AP}-3.0 \mathrm{~mm}, \mathrm{ML} \pm 3.5$ $\mathrm{mm}, \mathrm{VD}-5.0 \mathrm{~mm}$ relative to bregma). The needle was withdrawn 4 minutes after completion of the infusion; the pups were placed under a warming lamp and then returned to their mothers. On PD25 animals were weaned, separated by lesion status, and grouped two to three to a cage. A total of four cohorts $(n=20$ to $28 /$ cohort) of neonatally lesioned rats were utilized in the following experiments. In addition, a cohort of animals lesioned as adults (on PD42) was prepared as previously described (Lipska et al. 1992) for selected comparisons with neonatally lesioned rats.

\section{Behavioral Testing}

The motor activity of two different cohorts of rats $(n=$ 9 and 14 Sham, $n=11$ and 14 Lesion within each co. hort) was assessed at both 4 (PD35) and 7 weeks (PD56) postoperatively in three testing conditions: after exposure to a novel environment, after saline, and after amphetamine injection. Unacclimatized rats were moved to the monitor area at 9:00 AM and immediately placed in photocell activity monitors (model RXYZCM; Omnitech) for a 60-minute habituation period. After saline injection $(1 \mathrm{ml} / \mathrm{kg}, \mathrm{IP})$, each animal was returned to the photocell monitor for an additional 60 minutes. At that point, $d$-amphetamine (sulfate $1.5 \mathrm{mg} / \mathrm{kg}, \mathbb{P}$ ) (Sigma) was administered and activity was recorded for a final 90 minutes. 
One of these cohorts was additionally exposed to a swim test 2 weeks after the last testing (on PD70) to further explore the effects of stress in neonatally lesioned rats. Rats were randomly assigned to four groups (Sham/No Stress, Sham/Swim, Lesion/No Stress, Lesion/Swim, $n=8$ per group) and after acclimatization to the testing area, they were placed for 15 minutes in cylindrical plexiglass containers covered with opaque paper (height and diameter $30 \mathrm{~cm}$ ). The containers were flled either with sawdust $(2 \mathrm{~cm})$ (No Stress) or with water at room temperature (depth $23 \mathrm{~cm}$ ) (Swim). At the end of 15 minutes all animals were transferred to dry cages with new bedding; after 5 minutes they were then placed in photocell monitors. Locomotor activity was recorded for 95 minutes.

In a separate experiment, an additional group of rats was lesioned on PD42 as described previously (Lipska et al. 1992) and exposed to a swim test (on PD70) to compare the response to stress with a neonatally lesioned group. The lesion was induced as follows. After induction of anesthesia with Equithesin $3 \mathrm{ml} / \mathrm{kg}$ (IP), adult Sprague-Dawley rats (weight 220 to $240 \mathrm{~g}$ ) were placed in a Kopf stereotaxic instrument. Ibotenic acid $(6 \mu \mathrm{g} / 0.6 \mu$ l over 3 minutes) or an equal volume of vehicle was administered by infusion pump bilaterally ( 2 injections on each side) through 26-gauge cannulae at the coordinates $\mathrm{AP}-4.4 \mathrm{~mm}, \mathrm{ML} \pm 5.0 \mathrm{~mm}, \mathrm{VD}-8.0$ and $-6.0 \mathrm{~mm}$, with respect to bregma. Four weeks postoperatively (PD70), animals were randomly assigned to four groups Sham/No Stress, Sham/Swim, Lesion/No Stress, Lesion/Swim ( $n=10$ per group) and exposed to a swim test, as previously described. Locomotor activity was recorded for 95 minutes after the swim test.

Another neonatally lesioned test-naive cohort $(n=$ 10 Sham, $n=17$ Lesion) was tested only once at PD56 to control for the possibility that preexposure to amphetamine could affect the response on PD56.

Another group of rats lesioned at PD7 was treated for 3 weeks (from PD35 until PD56) with either vehicle (Veh) or haloperidol (Hal) to assess the effect of neuroleptic treatment on hyperlocomotion. The duration of treatment was chosen to approximate the subchronic duration of haloperidol administration associated with clinical response in patients with schizophrenia (Pickar 1988). At PD35, neonatally operated rats were randomly assigned to four groups: Sham/Veh, Lesion/Veh, Sham/Hal, Lesion/Hal, $n=7$ per group. The first two groups were treated once daily with vehicle (Veh, water with a drop of Tween 80 adjusted to $\mathrm{pH}$ 5.6) given intraperitoneally for 3 weeks, and the other two groups were injected with haloperidol $(\mathrm{Hal}, 0.4 \mathrm{mg} / \mathrm{kg}$, suspended in Veh) over the same period of time. One-half hour after the last dose of haloperidol (PD56), rats were placed in photocell monitors and their locomotion was assessed for 1 hour.

\section{Statistical Analysis}

All results were analyzed by analysis of variance (ANOVA) followed by post-hoc testing. Because in the two cohorts tested at both PD35 and PD56, there were no intercohort differences for the same lesion status in any motor-activity measure during any testing interval (i.e., habituation, saline, amphetamine), the data were combined according to the lesion status. For statistical analysis, vertical activity and total distance traveled were analyzed by ANOVA with status (Sham or Lesion) as an independent variable, and age (PD35 or PD56) and treatment (habituation, saline, $d$-amphetamine) as repeated measures. The Scheffé test was used for post-hoc comparisons. The results of the swim test were analyzed by ANOVA with status (Sham or Lesion) and Stress (Swim or No Stress) as independent variables followed by post-hoc tests. The results of haloperidol treatment were also analyzed by ANOVA with status (Sham or Lesion) and drug (Veh or Hal) as independent variables followed by post-hoc tests.

\section{RESULTS}

\section{Verification of the Neonatal Lesion}

Nissl-stained sections through the brains of lesioned rats showed sparing of the most anterior (dorsal) aspects of the hippocampal formation with neuronal loss, atrophy, and some cavitation in the VH (Fig. 1). The dentate gyrus and subiculum were also affected in more posterior (ventral) parts of the hippocampal formation (Fig. 2). In most brains, high-power microscopic investigation of the adjacent regions did not reveal any abnormal glial reaction, loss of neurons, or other obvious pathologic changes outside the primary lesion site. However, in a minority of cases (approximately $25 \%$ ), a small rim of gliosis with minimal neuronal loss could be detected in the thalamic region adjacent to the hippocampus (primarily in the lateral geniculate nucleus). Separate analysis of the behavioral results obtained from these animals did not show any significant differences from those without discernible extrahippocampal injuries. Therefore, these rats were not excluded from the study. In a few cases (5 of approximately 100 rats), histologic examination revealed more extensive damage outside the intended lesion site (neuronal loss and/or cavitation in the septum, cortex, or the thalamus). The results from these animals were excluded.

\section{Behavioral Experiments}

Exploration, Saline Injection, d-Amphetamine-Induced Hyperactivity. Analysis of vertical activity showed that during all three testing conditions (exploration in a novel environment, saline injection, and $d$-amphet- 


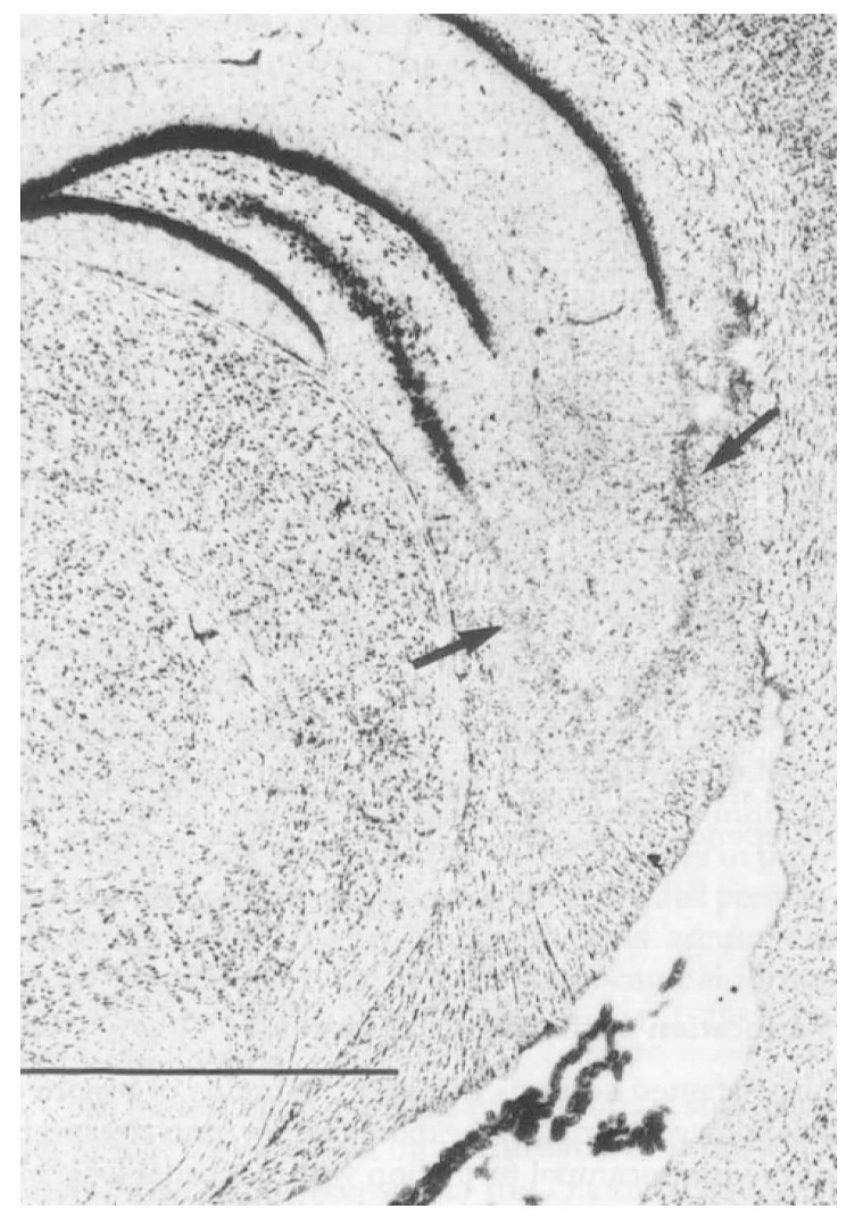

Figure 1. Nissl-stained coronal section (approximately 5.0 $\mathrm{mm}$ posterior from bregma) through the rat brain with neonatal ibotenic acid lesion of the $\mathrm{VH}$ formation. The rat was sacrificed 2 months after the lesion. Arrows point to areas of focal neuronal loss (CA3-4) with secondary microglial and astrocytic proliferation in the left hippocampus. The lesion extends further posterior (ventrally). Bar $=1 \mathrm{~mm}$.

amine administration), sham and lesioned animals were similar at PD35. At PD56, the lesioned animals were more active than controls during the exploration period and after amphetamine, (Fig. 3A). Analysis of variance revealed significant status $(F=4.85, p=0.03)$, age $(F=$ 99.26, $p<.001)$, and treatment $(F=139.9, p<.001)$ effects. There were significant status $\times$ treatment $(F=$ $4.60, p=.01)$ and age $\times$ treatment interactions $(F=$ 90.9, $p=.001)$. Both status $\times$ age $(F=3.62, p=.06)$ and status $\times$ age $\times$ treatment $(F=2.65, p=.07)$ interactions approached significance.

Similarly, total distance traveled by sham and lesioned animals did not differ at PD35; although at PD56 lesioned rats were more active than sham operates at all three testing intervals (Fig. 3B). Analysis of variance showed significant status $(F=9.71, p=.004)$, age $(F$ $=43.44, p=.001)$ and treatment $(F=232.8, p<.001)$ effects as well as status $\times$ treatment $(F=7.40, p=.001)$ and age $\times$ treatment $(F=36.52, p<.001)$ interactions. Status $\times$ age $(F=1.64, p=.21)$ and status $\times$ age $\times$ treatment $(F=.45, p=.64)$ interactions were not significant.

For the cohort tested at PD56 only, lesioned animals were hyperactive $(11316 \pm 973 \mathrm{~cm}, n=18)$ after $d$-amphetamine administration compared with Sham operates $(6762 \pm 682 \mathrm{~cm}, n=11, t$-test, $p=.002)$.

Swim Test. Moreover, neonatally lesioned animals showed increased activity after exposure to a swim stress at PD70 (Fig. 4). Analysis of variance revealed significant status $(F=5.55, p=.03)$ and stress effects $(F=70.65, p=.001)$, and a trend for a status $\times$ stress interaction $(F=3.65, p=.07)$. Although both sham and lesioned groups were more active in photocell monitors after swimming than after a control exposure (No Stress), the lesioned rats expressed increased locomotor activity after swim stress in comparison with Sham/Swim group $(p<.05)$. Such a stress effect was not seen in a cohort of rats lesioned as young adults (PD42) and also tested at PD70. In this case, ANOVA revealed a significant stress effect $(F=11.62, p=.002)$ but no status effect $(F=.01, p=.9)$ or status $\times$ stress interaction $(F=.07, p=.79)$.

Haloperidol Treatment. Treatment with haloperidol blocked the emergence of hyperactivity in a novel environment at PD56 in neonatally lesioned animals (Fig. 5). Analysis of variance revealed significant lesion ( $F$ $=7.05, p=.01)$ and drug $(F=5.4, p=.03)$ effects but no lesion $\times$ drug interaction $(F=1.1, p=.3)$. As before, the locomotor activity of Lesion/Veh group was significantly higher than that of Sham/Veh $(p<.05)$. However, the lesioned rats treated with haloperidol were significantly less active than lesioned, vehicletreated rats $(p<.05)$.

\section{DISCUSSION}

The results show that the effects of neonatal excitotoxic lesion of the $\mathrm{VH}$ in the rat are profoundly dependent upon the age of the animal. In particular, the effects of this lesion on regulation of behaviors most likely linked to mesolimbic DA activity emerge only after the animal has reached early adult life. Unlike similar lesions of $\mathrm{VH}$ produced during adulthood (Lipska et al. 1992), neonatal lesions did not affect spontaneous or amphetamine-induced locomotion 4 weeks postoperatively. This result was not surprising. Behavioral sparing has been observed after a variety of perinatal cortical lesions, including aspiration lesions of the hippocampus (Lanier and Isaacson 1977; Kolb and Whishaw 1989; Kolb and Gibb 1991). Also as expected (Remington and Anisman 1976), both PD35 and PD56 sham, as well as 


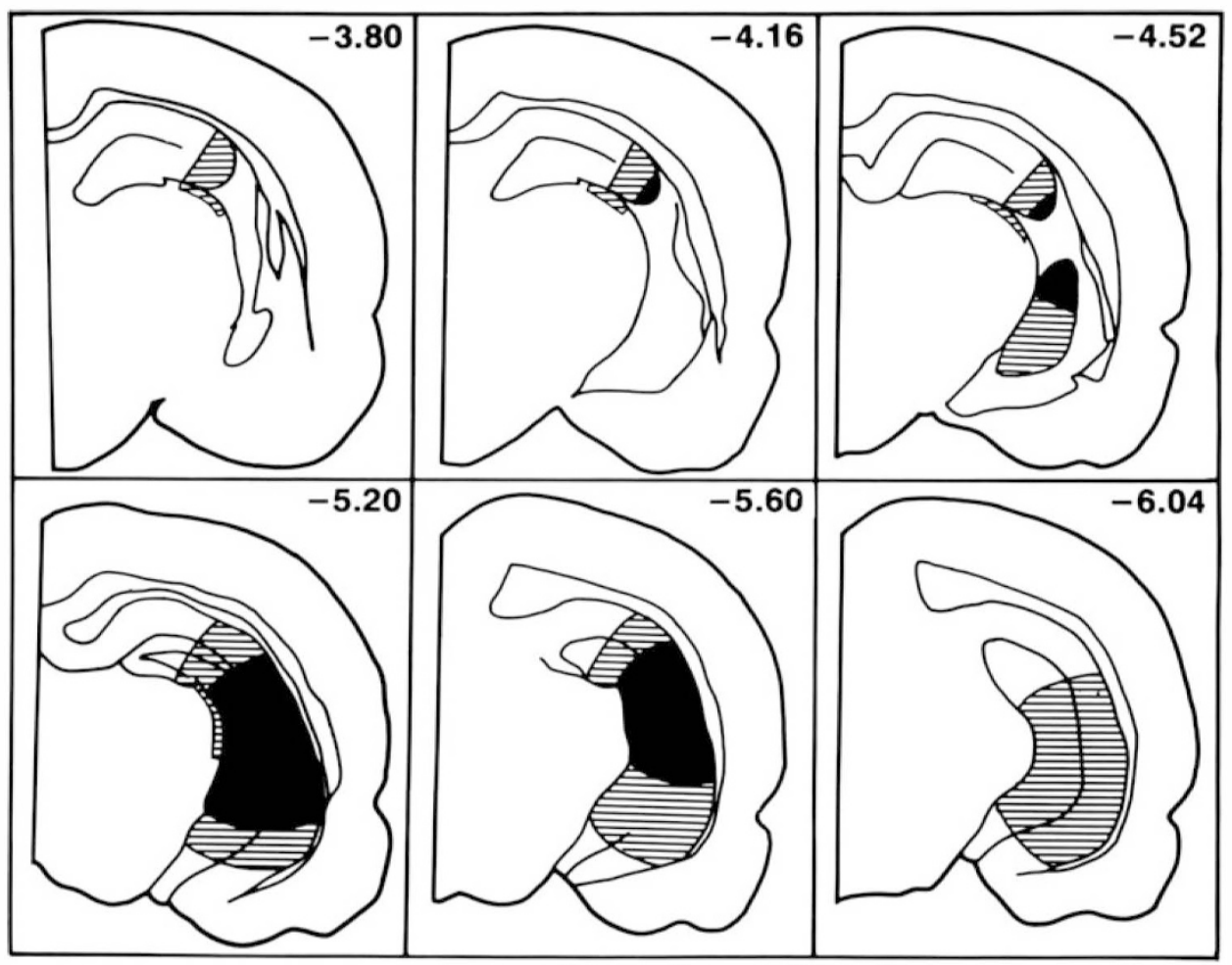

Figure 2. Lesion boundaries defined as the area of neuronal loss and gliosis and determined from Nissl-stained coronal sections from 20 rats with ibotenic acid lesion of the $\mathrm{VH}$ formation. Horizontal bars and solid black areas indicate the largest and smallest lesions, respectively. A small rim of injury in the adjacent thalamic region (primary lateral geniculate nucleus) was found in approximately $25 \%$ of cases.

A

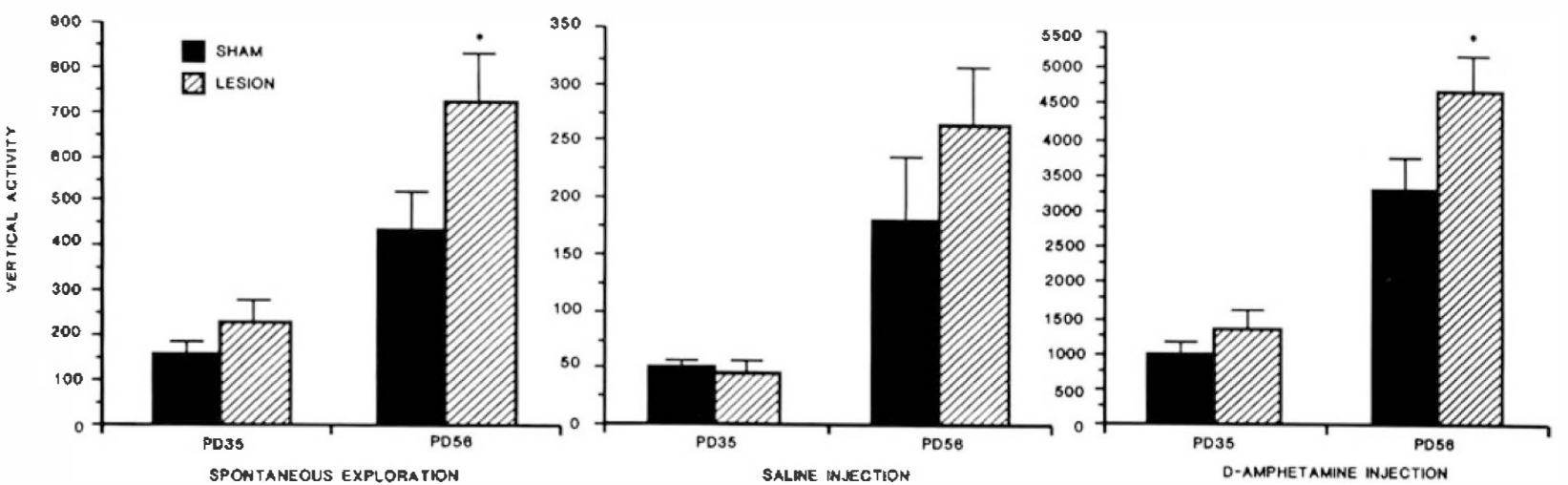

B
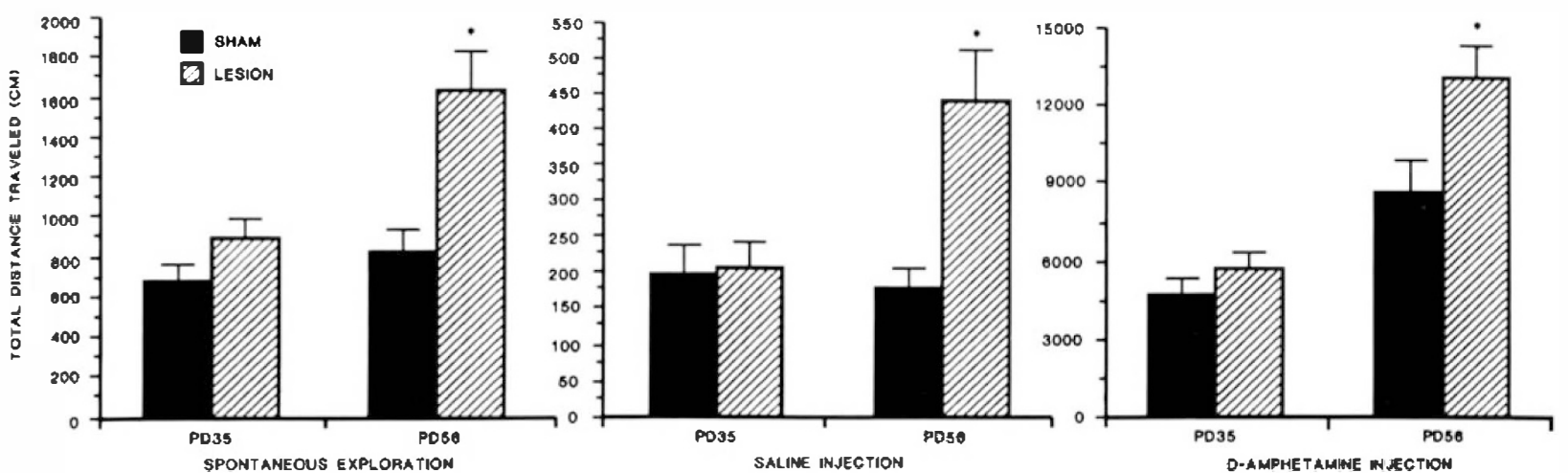

Figure 3. Locomotor activity of control (Sham) or ibotenic acid-injected (Lesion) groups tested at PD35 and PD56. ( $A$ ) Vertical activity (the total number of beam interruptions of the vertical sensor; (means \pm SEM, $n=20$ per group). At PD35, Lesion did not differ from Sham at any testing interval. At PD56 Lesion rats were more active than Sham rats during exploration and after amphetamine $(p<.05)$. (B) Total distance $(\mathrm{cm})$ traveled (means $\pm \mathrm{SEM}, n=20$ per group). At PD35, Lesion rats did not differ from Sham rats at any testing interval. At PD56, Lesion rats were more active than Sham rats at exploration $(p=.001)$, after saline $(p=.002)$, and after amphetamine $(p=.008)$.

- Lesion significantly different from Sham of the same age. 


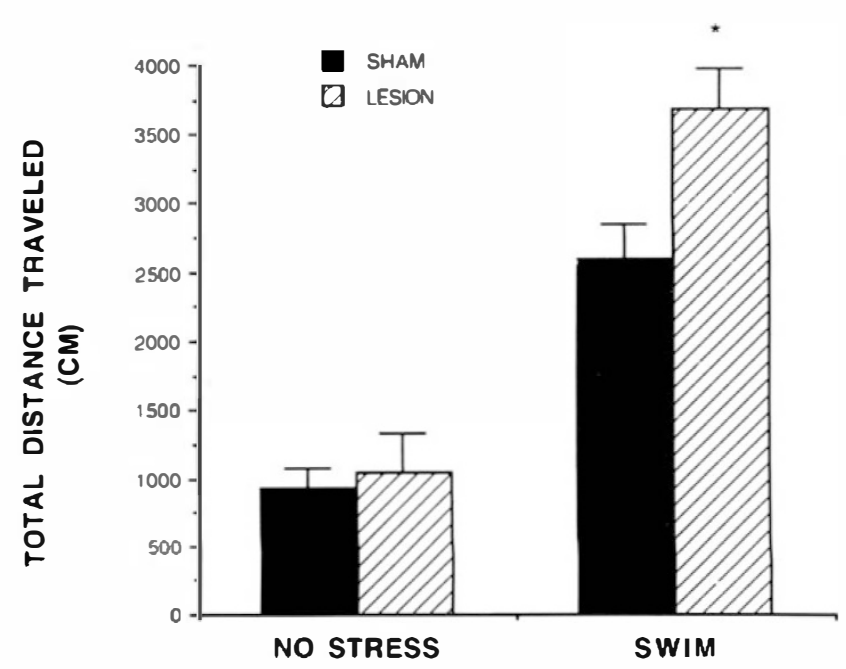

Figure 4. Total distance (means \pm SEM) traveled over 95 minutes of testing after 15-minute swim stress (Swim) or control exposure (No Stress) by rats with Sham or neonatal ibotenic acid lesion (Lesion) of the $\mathrm{VH}$ ( $\boldsymbol{n}=8$ per group).

* Lesion significantly different from Sham after exposure to a swim stress $(p<.05)$.

lesioned, animals responded to amphetamine administration with increased locomotor activity. Therefore, the failure of the neonatal lesion to differentially affect activity 4 weeks postoperatively, at PD35, cannot easily be attributed to immaturity of mechanisms mediating amphetamine-induced locomotion or to previously described developmental changes in the sensitivity of intrinsic hippocampal neurons to amphetamine (Jahromi 1991).

The absence of detectable lesion effects at PD35 contrasts with the increased locomotion in response to novelty, saline, or to amphetamine at PD56. Both novelty and amphetamine-induced locomotion have been linked to mesolimbic DA transmission (Pijenburg et al. 1975; Sharp et al. 1987). Saline injections also are known to increase accumbens DA turnover/release (Brose et al. 1987). Novelty, saline, and amphetamine may also have stresslike properties (Piazza et al. 1989; Piazza et al. 1991), which further implicate the limbic DA system. The fact that the emergence of hyperactivity can be blocked with an antidopaminergic drug (haloperidol) is also consistent with involvement of DA systems (Costall and Naylor 1976; Rupniak et al. 1985). The delayed locomotor changes cannot be attributed merely to differential stress or amphetamine-induced sensitization related to prior exposure, because similar changes were evident in neonatally lesioned rats that were exposed to amphetamine at PD56 only. Accordingly, the major finding of this study is that an excitotoxic lesion of the neonatal $\mathrm{VH}$ leads to the delayed emergence of behavioral changes suggestive of in-

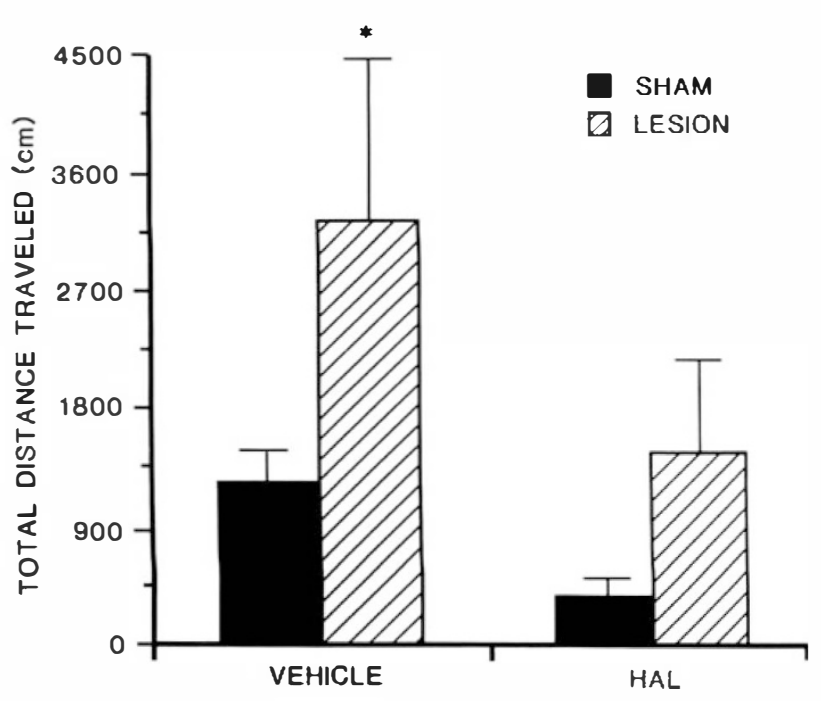

Figure 5. Total distance (means \pm SEM) traveled over 60 minutes after 3 weeks of Veh or Hal $(0.4 \mathrm{mg} / \mathrm{kg}$ IP) treatment by rats with Sham or neonatal ibotenic acid lesion (Lesion) of the VH. For details, see text.

* Significantly different from all other groups, $p<.05$.

creased mesolimbic DA responsivity to environmental as well as to pharmacologic stimuli.

There are several mechanisms by which limbiccortical regions may modulate mesolimbic DA transmission. Glutamatergic projections from the subiculum of the $\mathrm{VH}$ formation are believed to be in close apposition to mesolimbic DA axons innervating intrinsic cells of the NAC (Sesack and Pickel 1990) and have been strongly implicated in exploratory and in amphetamineelicited motor activity in the adult rat (Mogenson and Nielsen 1984; Mogenson and Wu 1991). The precise nature of the glutamate-DA interactions remains controversial (Freed 1989; Grace 1991). The hippocampal formation also sends excitatory projections to the prelimbic regions of the MPFC (Jay and Witter 1991), which in turn can affect both neurochemical and behavioral indices of striatal/limbic dopaminergic transmission (Jaskiw and Weinberger 1992a; Jaskiw et al. 1990a). Hippocampal lesions induced in adult rats are followed by changes consistent with a reduction of DA turnover in the MPFC (Lipska et al. 1992). In other paradigms, primary reductions in MPFC DA activity have been associated with enhanced limbic DA transmission (Pycock and Kerwin 1980; Deutch et al. 1990).

The absence of prepubertal motor changes after neonatal lesions could be mediated by changes in the pattern of neural projections (sprouting or rerouting) leading to sparing and functional recovery by PD35, but the ostensible failure of these mechanisms after puberty is puzzling. Alternatively, because the developmental stage at which hippocampal modulation of mesolimbic DA systems becomes behaviorally significant is not 
known, no true sparing may have occurred, as the contribution of the $\mathrm{VH}$ to mesolimbic DA-mediated behaviors might not have been functionally significant. Indeed, the possibility that the influence of the $\mathrm{VH}$ on DA systems does not become important until later in life would be a parsimonious explanation for the delayed effects we observed after the $\mathrm{VH}$ lesion. It is noteworthy in this regard that PD35 rats were prepubertal while PD56 rats were postpubertal (Baker 1979). Sexual maturation and attendant hormonal changes can influence dopaminergic systems as well as hippocampal physiology (Juraska 1991). Although the behavioral changes emerged after puberty, this fact in itself does not unequivocally prove a role for sexual maturation but nevertheless suggests such a possibility.

Another possible explanation for our findings, that of delayed secondary neurodegenerative changes, cannot be excluded. This possibility has been proposed to explain results of other studies that found changes in the expression of a neonatal lesion over time (Pearson et al. 1980; Saji and Reis 1987). However, there is a very important difference between our study and these earlier reports. Although these investigators described behavioral effects that change over time, the effects first appear early in life soon after the lesion. In contrast, in our study the changes first appear after a prolonged period of apparent normal behavior. By whatever mechanism, our model involves a developmental lesion and a prolonged period between the occurrence of the lesion and the emergence of its relevant behavioral effects.

It is also interesting to note that the behavioral changes after the neonatal lesion differed qualitatively in at least two respects from those we had previously observed after the analogous lesion in young adults. The latter is not associated with increased activity after saline injection (Lipska et al. 1992) or after a swim test, suggesting that the neonatal lesion induces a broader spectrum of hyperresponsivity to environmental stimuli, especially to stress. This finding raises the possibility that neonatal lesion of the $\mathrm{VH}$ affects the development of other neural systems implicated in the mesolimbic response to stress, such as the MPFC. Prefrontal function is particularly important in organizing responses to aversive stimuli and in regulating mesolimbic DA activity during stress (Jaskiw and Weinberger 1992a; Jaskiw and Weinberger 1990; Jaskiw et al. 1990b; Deutch and Roth 1990). In this regard, rats with neonatal lesions of the $\mathrm{VH}$ are similar to animals with MPFC lesions induced during adulthood, in that the latter also demonstrate enhanced locomotion after saline injection (Jaskiw et al. 1990a) or swim stress (Jaskiw and Weinberger 1992a). In contrast to lesions of the $\mathrm{VH}$ in adult animals that do not affect stress related mesolimbic DA activity, the early loss of hippocampal-prefrontal cortex connectivity could eventually have more profound consequences if such con- nectivity is critical to the maturation of the MPFC and to its influence on mesolimbic DA systems. Consistent with this possibility is evidence that the synaptic organization of PFC is immature prepubertally and continues to develop into adulthood (Kalsbeek et al. 1988).

It should be noted that we have not conclusively demonstrated the involvement of mesolimbic DA neural function. The influence of other brain systems on locomotor behavior can be demonstrated under certain conditions. However, overwhelming experimental evidence (Pijenburg et al. 1975; Brose et al. 1987; Sharp et al. 1987; Piazza 1991) indicates that hyperlocomotion under the constellation of test conditions in our study (novelty, stress, and amphetamine administration) is highly suggestive of increased mesolimbic DA activity. We are not familiar with any data that have shown a primary role of other systems in the mediation of locomotion during this constellation of conditions. It is important to note that hyperlocomotion during these conditions does not necessarily mean that there are increased concentrations of DA and metabolites. Other (e.g., postsynaptic) changes at or beyond the receptor may also play a role. Indeed, the behavioral changes may constitute the most compelling data of all, because they speak to the overall function of the system. This is analogous to what is seen in schizophrenia, where evidence of mesolimbic DA hyperactivity is indirectly inferred from the behavior of patients, from their sensitivity to amphetamine, and from their response to antidopaminergic treatment.

This model may provide an explanation for several aspects of schizophrenia that were not accounted for by earlier animal models; however, there are obvious limitations to this and any rat model of schizophrenia. The neuropathologic changes in the hippocampal formation after our lesion are more extensive than those reported in schizophrenia (for review, see Hyde et al. 1991). Moreover, we do not address neuropathologic abnormalities that have been reported outside the temporal lobe. Although we do not argue that only lesions of the $\mathrm{VH}$ produce this pattern of changes, and that only hippocampal abnormalities exist in schizophrenia, we do point out that developmental pathology of the $\mathrm{VH}$ can do this. Moreover, we do not address with this model the important evidence of a genetic liability to schizophrenia (for review, see Tsuang and Simpson 1988), and we have not as yet explored the effects of the lesion on cognition and cognitive development. Furthermore, the fundamental differences between rat and human brain probably represent an absolute limitation of the explanatory value of any rat model of a human illness involving perception, emotion, and cognition. In spite of these caveats, the model may be useful in exploring a variety of pathophysiologic mechanisms as well as new drug therapies.

In summary, in rats with neonatal ibotenic acid le- 
sions of the $\mathrm{VH}$, augmented activity in response to novelty, saline injection, and amphetamine administration develops only after puberty. Neonatal but not adultinduced $\mathrm{VH}$ lesions also produce an exaggerated response to stressful stimuli. These data are consistent with the interpretation that an early hippocampal lesion can remain silent with respect to certain behavioral parameters until early adulthood when its newly emergent consequences include increased responsivity to environmental and pharmacologic stimuli. Homologous mechanisms could be involved in schizophrenia, in which developmental temporal-limbic pathology is posited to remain relatively quiescent until onset of an illness in early adulthood that is characterized by stressinduced exacerbations, supersensitivity to amphetamine, and improvement with dopaminolytic drugs (for review, Jaskiw and Weinberger 1992b).

\section{REFERENCES}

Baker DEJ (1989): Reproduction and breeding. In Baker JH, Lindsey JR, Weisbroth SH (eds), The Laboratory Rat. New York, Academic Press, p 154-168

Berman KF, Weinberger DR (1991): Functional localization in the brain in schizophrenia. Am Psychiatr Press Rev Psychiatry 10:24-59

Bogerts B, Meertz E, Schonfeldt-Bausch R (1985): Basal ganglia and limbic system pathology in schizophrenia. Arch Gen Psychiatry 42:784-791

Borison RL, Havdala HS, Diamond BI (1977): Chronic phenyethylamine stereotypy in rats: A new animal model for schizophrenia? Life Sci 21:117-122

Brose N, O'Neill RD, Boutelle MG, Anderson SMP, Fillenz $M$ (1987): Effects of an anxiogenic benzodiazepine receptor ligand on motor activity and dopamine release in nucleus accumbens and striatum in the rat. J Neurosci 7:2917-2926

Buchsbaum MS, Ingvar DH, Kessler R(1982): Cerebral glucography with positron tomography. Arch Gen Psychiatry 39:251-259

Costall B, Naylor RL (1976): A comparison of the abilities of typical neuroleptic agents and of thioridazine, clozapine, sulpiride, and metoclopramide to antagonize the hyperactivity induced by dopamine applied intracerebrally to areas of the extrapyramidal and mesolimbic system. Eur J Pharmacol 40:9-18

Crow TJ (1990): Temporal lobe asymmetries as the key to the etiology of schizophrenia. Schizopr Bull 16:433-443

Csernansky JG, Kerr S, Pruthi R, Prosser ES (1988): Mesolimbic dopamine receptor increases two weeks following hippocampal kindling. Brain Res 449:357-360

Davis KL, Kahn RS, Ko G, Davidson M (1991): Dopamine in schizophrenia: A review and reconceptualization. Am J Psychiatry 148:1474-1486

Deutch AY, Roth RH (1990): The determinants of stressinduced activation of the prefrontal cortical dopamine system. Prog Brain Res 85:367-403

Deutch AY, Clark WA, Roth RH (1990): Prefrontal cortical depletion enhances the responsiveness of mesolimbic dopamine neurons to stress. Brain Res 521:311-315

Erinoff L, Snodgrass SR (1986): Effects of adult and neonatal treatment with 6-hydroxydopamine or 5,7-dihydroxytryptamine on locomotor activity, monoamine levels and response to caffeine. Pharmacol Biochem Behav 24:1039-1045

Ferino F, Thierry AM, Glowinski J (1987): Anatomical and neurophysiological evidence for a direct projection from Ammon's horn to the medial prefrontal cortex in the rat. Exp Brain Res 65:421-426

Fish B, Marcus J, Hans SL, Auerbach JG, Perdue S (1992): Infants at risk for schizophrenia: A sequelae of a genetic neurointegrative defect. A review and replication analysis of pandysmaturation in the Jerusalem Infant Development Study. Arch Gen Psychiatry 49:221-235

Freed WJ (1989): An hypothesis regarding the antipsychotic effect of neuroleptic drugs. Pharmacol Biochem Behav 32:337-345

Goldberg TE, Gold JM, Braff DL (1991): Neuropsychological functioning and time-linked information processing in schizophrenia. Am Psychiatr Press Rev Psychiatry 10:60-78

Goldman-Rakic PS, Selemon LD, Schwartz ML (1984): Dual pathways connecting the dorsolateral prefrontal cortex with the hippocampal formation and parahippocampal cortex in the rhesus monkey. Neuroscience 12:719-743

Grace AA (1991): Phasic versus tonic dopamine release and the modulation of dopamine system responsivity: a hypothesis for the etiology of schizophrenia. Neuroscience 41:1-24

Groenewegen HJ, Vermeulen-Van der Zee E, Te Kortschot A, Witter MP (1987): Organization of the projections from the subiculum to the ventral striatum in the rat. A study using anterograde transport of phaseolus vulgaris leucoagglutinin. Neuroscience 23:103-120

Hyde T, Casanova M, Kleinman JE, Weinberger DR (1991): Neuroanatomical and neurochemical pathology in schizophrenia. Am Psychiatr Press Rev Psychiatry 10:7-23

Jahromi SS, Niesen C, Carlen PL (1991): Amphetamine actions on pre- and postpubertal rat hippocampal dentate granule neurons. Brain Res 556:33-43

Jakob H, Beckmann H (1986): Prenatal development disturbances in the limbic allocortex in schizophrenics. J Neural Transm 65:303-326

Jaskiw GE, Weinberger DR (1990): Ibotenic acid lesions of the medial prefrontal cortex potentiate FG-7142-induced attenuation of exploratory activity in the rat. Pharmacol Biochem Behav 36:695-697

Jaskiw GE, Weinberger DR (1992a): Ibotenic acid lesions of medial prefrontal cortex augment swim-stress-induced locomotion. Pharmacol Biochem Behav 41:607-609

Jaskiw GE, Weinberger DR (1992b): Dopamine and schizophrenia - a cortically corrective perspective. Semin Neu. rosci 4:179-188

Jaskiw GE, Karoum F, Freed WJ, Phillips I, Kleinman JE, Weinberger DR (1990a): Effect of ibotenic acid lesions d the medial prefrontal cortex on amphetamine-induced locomotion and regional brain catecholamine concentrations in the rat. Brain Res 534:263-272 
Jaskiw GE, Karoum F, Weinberger DR (1990b): Persistent elevations in dopamine and its metabolites in the nucleus accumbens after mild subchronic stress in rats with ibotenic acid lesions of the medial prefrontal cortex. Brain Res 53:321-323

Jay T, Witter MP (1991): Distribution of hippocampal CA1 and subicular efferents in the prefrontal cortex of the rat studied by means of anterograde transport of phaseolus vulgaris-leucoagglutinin. J Comp Neurol 313:574-586

Juraska JM (1991): Sex differences in "cognitive" regions of the rat brain. Psychoneuroendocrinology 16:105-120

Kalsbeek A, Voorn P, Buijs RM, Pool CW, Vylings HBM (1988): Development of the dopaminergic innervation in the prefrontal cortex of the rat. J Comp Neurol 269:56-72

Kelley AE, Domesick VB (1982): The distribution of the projection from the hippocampal formation to the nucleus accumbens in the rat: An anterograde and retrograde horseradish peroxidase study. Neuroscience 7:2321-2335

Kennard MA (1936): Age and other factors in motor recovery from precentral lesion in monkeys. Am J Physiol 115: $138-146$

Kokkinidis L, Anisman H (1980): Amphetamine models of paranoid schizophrenia: An overview and elaboration of animal experimentation. Psychol Bull 88:551-579

Kolb B, Whishaw IQ (1989): Plasticity in the neocortex: Mechanisms underlying recovery from early brain damage. Prog Neurobiol 32:235-276

Kolb B, Gibb R (1991): Sparing of function after neonatal frontal lesions correlates with increased cortical dendritic branching: A possible mechanism for the Kennard effect. Behav Brain Res 43:51-56

Kornetsky C, Markowitz R (1978): Animal models of schizophrenia. In Lipton MA, DiMascio A, Killan KF (eds), Psychopharmacology: A Generation of Progress. New York, Raven Press, pp 583-593

Lanier LP, Isaacson RL (1977): Early developmental changes in the locomotor response to amphetamine and their relation to hippocampal formation. Brain Res 126:567-575

LeMoal M, Simon H (1991): Mesocorticolombic dopaminergic network: Functional and regulatory roles. Physiol Rev 71:155-234

Lipska BK, Jaskiw GE, Chrapusta S, Karoum F, Weinberger DR (1992): Ibotenic acid lesion of the ventral hippocampus differentially affects dopamine and its metabolites in the nucleus accumbens and prefrontal cortex in the rat. Brain Res 585:1-6

McKinney WT, Moran EC (1981): Animal models of schizophrenia. Am J Psychiatry 138:478-483

Mogenson GJ, Nielsen MAA (1984): A study of the contribution of hippocampal-accumbens-subpallidal projections to locomotor activity. Behav Neural Biol 42:38-51

Mogenson GJ, Wu M (1991): Effects of administration of dopamine D2 agonist quinpirole on exploratory locomotion. Brain Res 551:216-220

Pearson DE, Teicher MH, Shaywitz BA, Cohen DJ, Young JG, Anderson GM (1980): Environmental influences on body weight and behavior in developing rats after neonatal 6-hydroxydopamine. Science 209:715-717

Piazza PR, Deminiere JM, LeMoal M, Simon H (1989): Factors that predict individual vulnerability to amphetamine self-administration. Science 245:1511-1513
Piazza PV, Rouge-Pont F, Deminiere JM, Kharoubi M, LeMoal M, Simon H (1991): Dopaminergic activity is reduced in the prefrontal cortex and increased in the nucleus accumbens of rats predisposed to develop amphetamine selfadministration. Brain Res 567:169-174

Pickar D (1988): Perspectives on a time-dependent model of neuroleptic action. Schizophr Bull 14:255-268

Pickar D, Brier A, Hsiao JK (1990): CSF and plasma monoamine metabolites and their relation to psychosis: Implications for regional brain dysfunction in schizophrenia. Arch Gen Psychiatry 47:641-648

Pijenburg AJJ, Honig WMM, Van Rossum JM (1975): Inhibition of $d$-amphetamine induced locomotor activity by injection of haloperidol into nucleus accumbens of the rat. Psychopharmacologia 41:87-95

Pycock CJ, Kerwin RW, Carter CJ (1980): Effect of lesion of cortical dopamine terminals on subcortical dopamine receptors in rats. Nature 286:74-77

Remington R, Anisman H (1976): Genetic and ontogenic variations in locomotor activity following treatment with scopolamine and $d$-amphetamine. Dev Psychobiol 9: 579-585

Rupniak MJ, Hall MD, Kelly E, Fleminger S, Kilpatrick G, Jenner P, Marsden CD (1985): Mesolimbic dopamine function is not altered during continuous chronic treatment of rats with typical and atypical neuroleptic drugs. J Neural Transm 62:249-266

Saji M, Reis DJ (1987): Delayed transneuronal death of substantia nigra neurons prevented by gamma-aminobutyric acid antagonist. Science 235:66-69.

Sesack SR, Pickel VM (1990): In the rat medial nucleus accumbens, hippocampal and catecholaminergic terminals converge on spiny neurons and are in apposition to each other. Brain Res 527:266-271

Sharp T, Zetterstrom T, Ungerstedt U (1987): A direct comparison of amphetamine-induced behaviors and regional brain dopamine release in the rat using intracerebral microdialysis. Brain Res 401:322-330

Stevens JR (1992): Abnormal reinnervation as a basis for schizophrenia: A hypothesis. Arch Gen Psychiatry 49: 238-243

Tsuang MT, Simpson JC(1988): Nosology, epidemiology and genetics of schizophrenia. In Nasrallah HA (ed), Handbook of Schizophrenia, Vol. 3. New York, Elsevier

Weinberger DR (1987): Implications of normal brain development for the pathogenesis of schizophrenia. Arch Gen Psychiatry 44:660-669

Weinberger DR, Berman KF, Zec RF (1986): Physiological dysfunction of dorsolateral prefrontal cortex in schizophrenia. I: Regional cerebral blood flow (rCBF) evidence. Arch Gen Psychiatry 43:114-125

Weinberger DR, Berman KF, Illowsky B (1988): Physiological dysfunction of dorsolateral prefrontal cortex in schizophrenia. III: A new cohort and evidence for a monoaminergic mechanism. Arch Gen Psychiatry 45: 609-615

Yang CR, Mogenson GJ (1985): An electrophysiological study of the neural projections from the hippocampus to the ventral pallidum and the subpallidal areas by way of the nucleus accumbens. Neuroscience 15:1015-1024 